\title{
Aplikasi Data Mining dalam Penentuan Layout Swalayan dengan Menggunakan Metode MBA
}

\author{
Muhammad Rizki ${ }^{*}$, Desi Devrika ${ }^{2}$, Fitriani Surayya Lubis ${ }^{3}$, Silvia $^{4}$, Isnaini Hadiyul Umam ${ }^{5}$ \\ 1,2,3,4,5 Jurusan Teknik Industri Fakultas Sains dan Teknologi, UIN Sultan Syarif Kasim Riau-Indonesia \\ Jl. HR. Soebrantas No. 155 Simpang Baru, Panam, Pekanbaru, 28293 \\ muhammad.rizki@uin-suska.ac.id
}

\begin{abstract}
ABSTRAK
Data mining merupakan salah satu cara untuk mendapatkan informasi yang tersimpan pada dabased yang berjumlah besar. Data transaksi penjualan pada sebuah swalayan sering kali hanya digunakan sebagai laporan penjualan saja. Dalam kenyataannya, data tersebut dapat memberikan informasi yang lebioh dari sekedar laporan penjualan saja. Salah satu informasi yang dapat kita ambil dari data transaksi penjualan adalah hubungan antar item. Kita dapat mengetahui kelompok item yang cenderung dibeli bersamaan oleh pelanggan dalam satu transaksi pembelian.. Market Basket Analysis (MBA) merupakan salah satu metode untuk menentukan kelompok item yang cenderung dibeli oleh pelanggan dalam satu waktu atau dalam satu transaksi pembelian. Informasi keterkaitan antar kelompok item tersebut dapat kita jadikan sebagai referensi untuk menentukan layout, dimana item yang sering dibeli bersamaan kita dekatkan dalam penataan layoutnya sehingga pelanggan tidak perlu lagi susah payah untuk mencari item tersebut. Berdasarkan studi kasus awal pada salah satu swalayan yang berada di Pekanbaru, penataan layout per clusternya dilakukan secara acak, sehingga pelanggan kesulitan untuk mencari item-item yang biasanya dibeli dalam satu kali transaksi. Pemilik swalayan menginginkna penataan layout ulang mengikuti pola pembelian pelanggan. Pettern growth merupakan salah satu Teknik dari MBA, dimana hasil analisis dapat diketahui kelompok item yang memiliki kecendrungan untuk dibeli bersamaan oleh pelanggan.
\end{abstract}

Kata Kunci: Data Mining, MBA, Association Rule, Pattern Growth, laYout

\section{Pendahuluan}

XX merupakan salah satu swalayan yang terdapat di Pekanbaru yang menyediakan beraneka macam produk. Berdasarkan wawancara dengan pemilik XX Swalayan, perancangan layout yang dilakukan oleh XX Swalayan secara garis besar dibagi menjadi dua cluster yaitu Food dan Non Food. Namun penataan layout perclusternya dilakukan secara random dan bukan didasarkan pada pola pembelian pelanggan. Pemilik XX Swalayan menginginkan agar dikalukan penataan ulang layout clusternya berdasarkan pola pembelian pelanggan. Oleh karena itu diperlukan studi untuk menyelesaikan masalah diatas yaitu dengan menggunakan MBA yang merupakan salah satu teknik dari data mining.

Beberapa metode yang pernah digunakan dalam MBA diantaranya adalah metode data dengan menggunakan metode graf asosiasi. Metode ini memiliki kelemahan mengolah data dalam memori yang besar. Keterbatasan memori sangat mempengaruhi data item yang diproses sehingga membutuhkan komputasi yang lama.

Untuk memperbaikinya diterapkan metode apriori yang menggunakan paradigma candidate generation and test. Metode apriori juga mempunyai kelemahan pada paradigma candidate generation and test yaitu membangkitkan kandidat aturan asosiasi dalam jumlah besar sehingga aturan asosiasi akan meningkat secara eksponensial apabila polanya panjang. Walaupun dari segi ketelitian metode apriori cukup baik, namun karena banyaknya aturan asosiasi yang dihasilkan membuat overfitting yang mengandung redundant, misleading rules dan tidak membawa informasi yang dibutuhkan yang membuat kualitas informasi dari aturan asosiasi yang didapat menjadi menurun. Aturan asosiasi dalam jumlah besar yang dibangkitkan oleh metode apriori menjadi bermasalah karena tingkat generalization yang rendah dari metode ini, sehingga muncul persoalan bahwa aturan yang dihasilkan dalam jumlah besar perlu untuk dikurangi.

Metode pattern growth adalah metode yang dapat memperbaiki metode sebelumnya yaitu metode apriori. Metode pattern growth mampu menjawab persoalan yang 
dihadapi metode apriori yaitu mengurangi aturan yang dibangkitkan dalam jumlah besar karena tingkat generalizationnya yang rendah. Metode ini memperlihatkan bahwa dalam melakukan pencarian kaidah asosiasi hanya membutuhkan dua kali pembacaan basis data dan tidak memerlukan pengetesan kandidat. Aturan asosiasi yang dihasilkan dari metode pattrern growth ini kemudian diketahui pola kebiasaan pelanggan sehingga dapat diterapkan usulan rancangan layout item dalam area yang berdekatan sebagai aplikasi dari MBA. Dengan Susunan layout yang bersifat menguntungkan ini jarak yang harus dilalui oleh pelanggan untuk mendapatkan barang yang dicari relatif lebih dekat. Dengan demikian waktu yang digunakan untuk mencari barang tersebut juga semakin singkat.

\section{Tinjauan Pustaka}

\section{Knowlegde Discovery in Database}

Knowledge Discovery in Database (KDD) adalah keseluruhan proses untuk mencari dan mengidentifikasi pola dalam data, dimana pola yang ditemukan bersifat sah, baru, dapat bermanfaat dan dapat dimengerti. KDD berhubungan dengan teknik integrasi dan penemuan ilmiah, interprestasi dan visualisasi dari pola-pola sejumlah kumpulan data. Menurut Kapiudin (2007) KDD dan data mining sering kali digunakan secara bergantian untuk menjelaskan proses penggalian informasi tersembunyi dalam suatu basis data yang besar. Sebenarnya kedua istilah tersebut memiliki konsep yang berbeda akan tetapi berkaitan satu dengan yang lain.

Menurut Fayyad et.al., (1996) KDD digambarkan sebagai proses penggunaan metode data mining untuk menemukan informasi bermanfaat dan pola didalam data, sedangkan data mining menggunakan algoritma untuk mengidentifikasi pola-pola didalam data yang didapatkan dari proses KDD sehingga KDD adalah salah suatu proses menyeluruh yang meliputi data mining. Beberapa tahapan dalam proses KDD adalah sebagai berikut :

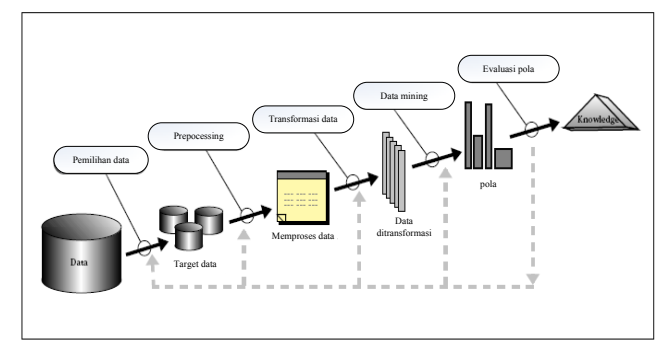

Gambar 1. Knowledge Discovery in Database 1. Pemilihan data

Merupakan proses Pemilihan atau penyeleksian data dari sekumpulan data operasional yang dilakukan sebelum tahap penggalian informasi dalam KDD dimulai. Dalam tahapan ini, kita memilih data-data seperti apa saja yang kita butuhkan untuk diproses lebih lanjut.

2. Preprocessing

Pada umumnya data yang diperoleh, baik dari database suatu perusahaan maupun hasil eksperimen, memiliki isian-isian yang tidak sempurna seperti data yang hilang, data yang tidak valid atau juga hanya sekedar salah ketik. Selain itu, ada juga atribut-atribut data yang tidak relevan dengan hipotesa data mining yang kita miliki. Data-data yang tidak relevan itu juga lebih baik dibuang karena keberadaannya bisa mengurangi mutu atau akurasi dari hasil data mining nantinya. "Garbage in garbage out" (hanya sampah yang akan dihasilkan bila yang dimasukkan juga sampah) merupakan istilah yang sering dipakai untuk menggambarkan tahap ini. Pembersihan data juga akan mempengaruhi performansi dari sistem data mining karena data yang ditangani akan berkurang jumlah dan kompleksitasnya.

\section{Transformasi data}

Beberapa teknik data mining membutuhkan format data yang khusus sebelum bisa diaplikasikan. Sebagai contoh beberapa teknik standar seperti analisis asosiasi dan clustering hanya bisa menerima input data kategorikal. Karenanya data berupa angka numerik yang berlanjut perlu dibagi-bagi menjadi beberapa interval. Proses ini sering disebut binning. Disini juga dilakukan pemilihan data yang diperlukan oleh teknik data mining yang dipakai. Transformasi dan pemilihan data ini juga menentukan kualitas dari hasil data mining nantinya karena ada beberapa karakteristik dari teknik-teknik data mining tertentu yang tergantung pada tahapan ini.

\section{Data Mining}

Data mining merupakan proses untuk mencari pola atau informasi menarik dalam data terpilih dengan menggunakan teknik atau metode tertentu (Santoso, 2007). Teknik, metode atau algoritma dalam data mining 
sangat bervariasi. Pemilihan metode atau algoritma yang tepat sangat bergantung pada tujuan dan proses KDD secara keseluruhan.

5. Evaluasi pola

Dalam proses ini, pola-pola yang telah diidentifikasi oleh sistem kemudian diterjemahkan ke dalam bentuk knowledge yang mudah dimengerti oleh pihak yang berkepentingan

\section{Data Mining}

Kemajuan dalam pengumpulan data dan teknologi penyimpanan yang cepat memungkinkan organisasi menghimpun jumlah data yang sangat luas (Netz et.al., 2000). Pengolahan data menggunakan teknik analisis yang tradisional tidak dapat digunakan untuk mengekstrak informasi yang ada pada dabased dalam, jumlah yang besar. Data mining merupakan metode yang menggabungkan teknik tradisional dan teknologi dimana databased yang berukuran besar dapat diolah datanya dengan cepat dan tepat

Menurut Han dan Kamber (2001) data mining adalah proses menemukan pattern didalam data yang berjumlah besar dimana proses penemuan tersebut dilakukan secara otomatis atau semi otomatis menggunakan komputer dan pattern ditemukan harus bermanfaat. Sedangkan pengertian data mining menurut Gunawan (2003), data mining adalah teknik untuk menambang data sehingga didapat informasi yang sebelumnya sulit diperoleh.

Dari pengertian diatas, dapat disimpulkan bahwa data mining adalah analisis terhadap data set untuk menemukan hubungan dan menyimpulkan data dengan cara yang jelas, dimana hasilnya dapat dimengerti dan berguna bagi pemilik data.

\section{Market Basket Analysis (MBA)}

MBA adalah salah satu teknik data mining yang bertujuan untuk menemukan produk-produk yang sering dibeli bersamaan dari data transaksi (Boztu ־ \& Hildebrant, 2005). Association rule mining adalah suatu prosedur untuk menemukan aturan assosiatif antara suatu kombinasi item. Contoh dari aturan asosiasi dari analisa pembelian di suatu pasar swalayan adalah bisa diketahui berapa besar kemungkinan seorang pelanggan membeli roti bersamaan dengan Susu bayi. Dengan pengetahuan tersebut pemilik pasar swalayan dapat mengatur penempatan barang dalam area tertentu (Suwarningsih, 2008)

Penting tidaknya suatu aturan asosiasi dapat diketahui dengan Metodologi dasar analisis asosiasi yaitu :

1. Analisa pola frekuensi tinggi

2. Pembentukan aturan asosiasi

3. Lift ratio

MBA memiliki banyak pendekatan salah satunya Pattern growth. Dalam menentukan himpunan data (frequent itemset) pada database sehingga didapatkan association rule. Pengembangan dari penggunaan pohon prefix atau yang biasa disebut Frequent Pattern Tree (FP Tree) digunakan untuk mencari frequent itemset tersebut.

\section{Perancangan Layout}

Pengertian perancangan fasilitas dapat dikemukakan sebagai proses perancangan fasilitas, termasuk didalamnya analisis, perencanaan, desain dan Susu bayinan fasilitas, peralatan fisik dan manusia yang ditujukan untuk meningkatkan efisiensi dan sistem pelayanan (Purnomo, 2004). Mengatur penempatan item di swalayan merupakan salah satu aplikasi dari MBA. Penempatan item ini didapat dari analisa pembelian konsumen dengan melihat dari seberapa besar kemungkinan seorang pelanggan setelah membeli item $X$ akan membeli item $Y$. Aturan asosiasi dan nilai confidence adalah yang menunjukkan antara suatu kombinasi item tersebut (Surjandari \& Seruni, 2005). Aturan asosiasi akan memperlihatkan kombinasi antar item sedangkan nilai confidence inilah yang akan memperlihatkan hubungan kuat lemahnya antara item $X$ dan item $Y$ sehingga kedua item tersebut penempatannya akan didekatkan atau dijauhkan. Jika item $X$ dan Item $Y$ didekatkan diharapkan konsumen akan konsumen akan tertarik membeli item $Y$ setelah membeli item $Y$. Jika dijauhkan diharapkan agar dalam proses pencarian kedua item tersebut konsumen tertarik untuk membeli item lain yang tidak direncanakan sebelumnya

\section{Activity Relationship Chart}

Dalam perancangan tata letak salah satu analisis yang bersifat kualitatif adalah Activity Relationship Chart (ARC). Analisis ARC ini dikembangkan oleh Muther yang merupakan analisis sederhana dalam merencanakan tata letak fasilitas. Analisis ini menghubungkan aktivitas secara berpasangan sehingga semua aktivitas akan 
diketahui tingkat hubungannya (Purnomo, 2004). ARC mempunyai variabel untuk menggantikan angka-angka yang bersifat kuantitatif. Variabel tersebut berupa simbol yang melambangkan derajat kedekatan antara departemen satu dengan departemen yang lainnya. Simbol-simbol yang digunakan untuk menunjukkan derajat keterkaitan aktivitas adalah sebagai berikut :

$$
\begin{array}{ll}
\mathrm{A} & =\text { mutlak perlu } \\
\mathrm{E} & =\text { sangat penting } \\
\mathrm{I} & =\text { penting } \\
\mathrm{O} & =\text { cukup/ biasa } \\
\mathrm{U} & =\text { tidak penting } \\
\mathrm{X} & =\text { tidak dikendaki }
\end{array}
$$

\section{Metode Penelitian}

Perkembangan teknologi informasi sejak tahun 1990an memungkinkan data dalam jumlah besar terakumulasi. Tetapi pertumbuhan yang pesat dari akumulasi data itu telah menciptakan kondisi yang sering disebut sebagai kaya akan data namun miskin informasi, karena data yang terkumpul itu tidak dapat digunakan untuk aplikasi yang berguna. Data transaksi penjualan pada sebuah swalayan sering kali hanya digunakan sebagai laporan penjualan saja. Dalam kenyataannya, data tersebut dapat memberikan informasi yang lebioh dari sekedar laporan penjualan saja. Salah satu informasi yang dapat kita ambil dari data transaksi penjualan adalah hubungan antar item. Kita dapat mengetahui kelompok item yang cenderung dibeli bersamaan oleh pelanggan dalam satu transaksi pembelian. Salah satu cara yang dapat dilakukan untuk menggali pola perilaku pemilihan barang oleh pelanggan tersebut adalah dengan menggunakan teknik MBA. Pengetahuan tentang pola perilaku untuk mengetahui kecenderungan item yang dibeli pelanggan tersebut dimanfaatkan untuk menyusun tata letak barang di swalayan. Perancangan ulang tata letak barang dilakukan berdasarkan hasil dari MBA dengan menggunakan metode pattern growth. Berdasarkan identifikasi masalah diatas maka dalam penelitian ini akan diusulkan suatu rancangan tata letak layout barang yang berdasarkan pola perilaku pemilihan barang berdasarkan kecenderungan konsumen dalam membeli barang

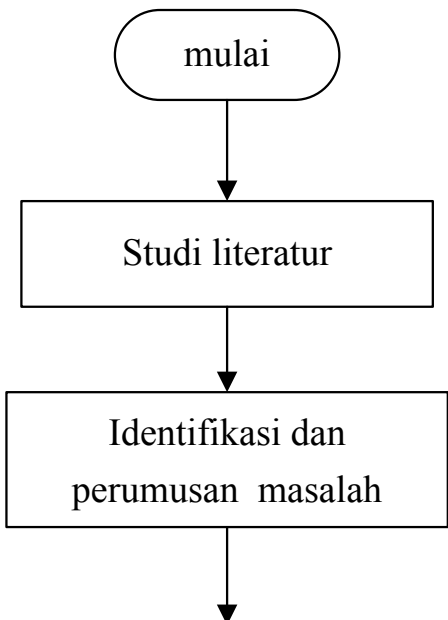

Pengumpulan dan pengolahan data meliputi:

1. Tahapan pemilihan data

2. Preprocessing data meliputi

a. Pembersihan data

b. Data integrasi

\section{Market Basket Analysis}

4. Metode Pattern Growth

5. Pola hubungan antar produk

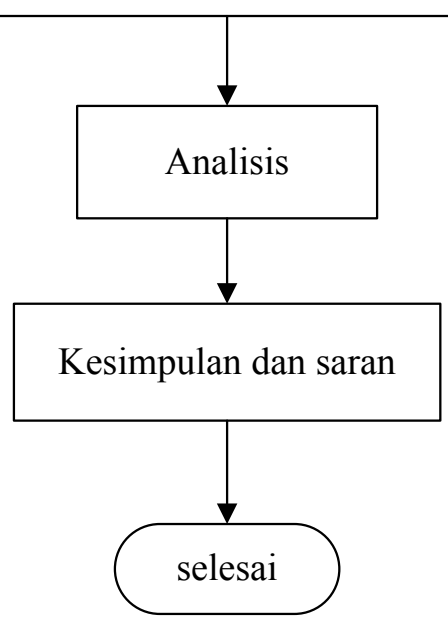

Gambar 2 Diagram Alir Kerangka Penelitian

Adapun penjelasan diagram alir dalam penelitian diatas adalah sebagai berikut :

\section{Studi Literatur}

Dua metode study literatur yaitu :

\section{Kajian Deduktif}

Kajian ini bertujuan untuk membangun konseptual dengan fenomena- fenomena yang dapat disistematika, diklasifikasikan dan dihubung- hubungkan sehingga bersifat umum. Kajian deduktif merupakan 
landasan teori yang dipakai sebagai acuan untu memecahkan penelitian

\section{Kajian Induktif}

Kajian induktif merupakan kajian pustaka yang bertujuan utnuk menjaga originalitas penelitian dan untuk pengembangan ilmu pengetahuan khususnya pada topik tersebut. Referensi yang digunakan yaitu junal, prosiding, dan beberapa tugas akhir mahasiswa. Pada kajian ini dapat di ketahui posisi penelitian tersebut, dimana penelitianpenelitian terdahulu akan berkaitan erat pada penelitian ini, sehingga kekurangan-kekurangan yang menjadi batasan masalah pada penelitan sebelumnya dapat ditutupi pada penelitian ini. Disamping itu, perkembangan metodemetode yang ada pada MBA dapat diketahui.

\section{Identifikasi dan perumusan masalah}

Setelah selesai pada tahap kajian pustaka dilanjutkan dengan merumuskan masalah apa yang menjadi masalah dalam studi kasus kemudian ditetapkan batasan-batasan agar penelitian yang dilakukan tidak biasa serta agar tujuan dari penelitian dapat tercapai. Salah satu teknik yang dapat digunakan untuk menganalisa pola perilaku konsumen adalah dengan menggunakan teknik MBA. Salah satu teknik data mining yang bertujuan untuk menemukan pola perilaku konsumen untuk menentukan item yang biasanya dibeli bersamaan dalam satu transaksi adalah market basket analysis. Dengan menggunakan teknik ini, maka dapat ditentukan barang yang dibeli secara bersamaan oleh konsumen

\section{Pengumpulan dan pengolahan data}

Pengambilan data dilakukan di XX swalayan di Pekanbaru. Sumber data yang dikumpulkan berupa informasi database transaksi penjualan pada periode Januari hingga Juli 2019. Keseluruhan data ini digunakan untuk penggalian informasi. Sedangkan pengolahan data meliputi tahapan pemilihan data, preprocessing data meliputi pembersihan data, data integrasi, kemudian teknik yang digunakan adalah MBA dengan menggunakan metode pattern growth untuk menemukan pola hubungan antar produk. Proses pada pengambilan data yang dilakukan adalah sebagai berikut :

1. Database transaksi penjualan pelanggan

2. Data umum yang diperlukan

3. Gambaran tata letak layout barang yang sedang digunakan saat ini (tata letak awal)

Sedangkan pada pengolahan data yang meliputi tahapan pemilihan data, preprocessing data meliputi pembersihan data, data integrasi, Market Basket Analysis,
Pattern Growth, dan pola hubungan antar produk dan dapat dijelaskan sebagai berikut :

1. Pemilihan data

Pada tahap ini data yang dipilih adalah database transaksi penjualan dari XX swalayan pada bulan Januari sampai Juli 2019

2. Prepocessing data

Dalam prepocessing data meliputi :

a. Pembersihan data

Tujuan dari pembersihan data adalah untuk membersihkan data transaksi penjualan dari kesalahan data, dan untuk menghilangkan noise. Contoh dari data cleaning adalah untuk menghilangkan tanggal, nomor faktur, harga, jumlah, diskon, netto

b. Data integrasi

Data integrasi adalah processing data dimana terjadi tahap pengurangan data. Dalam hal ini akan menghabiskan banyak waktu dan menjadikan banyak hasil yang tidak berguna jika memasukkan beberapa item yang memang tidak akan termasuk dalam eksplorasi. Dari data yang ada, masingmasing item dihitung jumlah kuantitasnya. Proses ini bertujuan untuk menyederhanakan ragam atau jenis produk kedalam suatu cluster.

\section{Market Basket Analysis (MBA)}

1. Menentukan nilai support

Support adalah persentase kombinasi item dalam database. Nilai support ini dapat dicari seperti pada persamaan 1

$$
\text { Sщuport }=\mathrm{p}(\mathrm{A} \cap \mathrm{B})=\frac{\text { jumlah transaksi yang memuat } \mathrm{A} \text { dan } \mathrm{B}}{\text { total jumlah transaksi }}
$$

2. Menentukan nilai confidence

Nilai confidence menunjukkan kuatnya hubungan ketika seorang pelanggan membeli item $X$, maka akan membeli item $\mathrm{Y}$ dalam aturan assosiatif. Nilai confidence ini dapat dicari seperti pada persamaan 2

Confidence $=P(\mathrm{~B} / \mathrm{A})=\frac{\text { Support }(A \cap B)}{\mathrm{P}(A)}$

3. Menentukan nilai lift ratio

Lift Ratio adalah parameter penting selain support dan confidence dalam association rule. Lift ratio merupakan nilai prediktor. Nilai lift ratio yang baik digunakan sebagai prediktor adalah lift ratio yang mempunyai nilai lebih dari 1. Nilai 
confidence ini dapat dicari seperti pada persamaan 3

$$
\text { Lift Ratio }=\frac{\text { Confidence }(\mathrm{B} / \mathrm{A})}{\text { Support } \mathrm{B}}
$$

\section{Metode Pattern Growth}

Pattern Growth adalah salah satu metode dalam pendekatan MBA yang dapat digunakan untuk menentukan himpunan data yang sering muncul (frequent itemset) dalam sebuah database yang besar sehingga didapatkan association rule. Tahap dalam mencari aturan asosiasi adalah sebagai berikut :

\section{FP-Tree}

FP-Tree merupakan struktur data yang dimampatkan. FPTree dibangun dengan memetakan setiap data transaksi kedalam setiap lintasan tertentu dalam FP-Tree. Setelah didapatkan struktur FP-Tree kemudian dilanjutkan dengan membangkitkan FP-Growth

\section{FP-Growth}

Dibawah ini adalah tiga langkah utama penyusunan FPGrowth :

1. Tahap Pembangkitan Conditional Pattern Base

2. Tahap Pembangkitan Conditional FP- Tree

3. Tahap pencarian frequent itemset

\section{Pola hubungan antar produk}

Association rule yang dihasilkan dari metode pattern growth, kemudian diSusu bayin hubungan dari tiap item Yarang dengan menggunakan nilai confidence untuk merencanakan tata letak barang

\section{Analisis}

Dalam penggolongan data menggunakan teknik Market Basket Analysis hasil pengolahan data tersebut akan dianalisis dan digunakan untuk proses pengambilan keputusan dalam penyusunan tata letak barang. Analisa dilakukan dengan menggunakan nilai confidence dari setiap association rule, evaluasi data letak barang awal, analisa hubungan aturan antar item untuk mendesain ulang tata letak barang

\section{Kesimpulan dan saran}

Setelah melakukan analisa dari pengolahan data yang telah dilakukan, maka pada tahap ini dapat ditarik kesimpulan hasil penelitian yang telah dilakukan dan pemberian saran untuk mengembangkan hasil penelitian ini pada penelitian selanjutnya

\section{Hasil dan Pembahasan}

\section{Analisa MBA}

Dengan menggunakan metode Pattern Gowth dimaksudkan untuk mendapatkan aturan asosiasi dari database transaksi. Dari Tabel 4.6 aturan asosiasi yang diperoleh sebanyak 44 rule. Salah satu contoh aturan asosiasi adalah sebagai berikut :

Beverages $\rightarrow$ cemilan

Nilai parameter market basket analysisnya adalah support sebesar $7.429 \%$, nilai confidence sebesar $41.925 \%$ dan nilai lift ratio sebesar 2.669

Nilai support menunjukkan kombinasi item dalam database. Nilai confidence menunjukkan kuatnya hubungan ketika seorang pelanggan membeli item $X$, maka akan membeli item $Y$ dalam aturan assosiatif. Dan lift ratio adalah sebagai nilai prediktor. lift ratio yang mempunyai nilai lebih dari 1 disebut juga dengan rule yang positif, nilai ini mempunyai pengertian bahwa hasil rule yang didapatkan sekarang adalah rule yang baik untuk memprediksi pola yang sama berdasarkan frekuensi item. Dari aturan asosiasi diatas menunjukkan bahwa kombinasi item beverages dan item cemilan dalam keseluruhan database sebanyak $7.429 \%$. Untuk mengetahui kuatnya hubungan antara kedua item tersebut adalah dengan nilai confidence. Nilai confidence ini mempunyai pengertian bahwa kecenderungan pelanggan untuk membeli item beverages kemudian membeli item cemilan sebesar $41.925 \%$ dari keseluruhan transaksi. Kemudian nilai lift ratio 2.8 menunjukkan bahwa aturan asosiasi ini baik untuk memprediksi pola yang sama berdasarkan frekuensi item dari data transakasi karena nilai lift ratio yang pada aturan asosiasi beverages $\rightarrow$ cemilan sebesar 2.8 lebih dari 1

\section{Analisa hubungan antar item}

Pola perilaku pembelian yang terbentuk dari penelitian ini menyatakan bahwa sebagian besar item yang terpilih mendorong terjadinya pembelian pada item beverages karena beverages adalah item yang paling sering dalam data tranasaksi. Nilai confidence yang diperoleh dari persamaan 2.3 memperlihatkan pola hubungan antar item yang dapat digambarkan dengan menggunakan ARC. Berdasarkan hasil yang diperoleh sebelumnya dengan menggunakan metode Pattern Growth, hubungan kuat antar cluster dinyatakan dengan nilai 
confidence $29.63 \%$ sampai dengan 44.44\%, hubungan sedang antar cluster dinyatakan dengan nilai $14.81 \%$ sampai dengan $29.62 \%$. hubungan lemah antar cluster dinyatakan dengan nilai $0 \%$ sampai dengan $14.80 \%$. Berikut adalah contoh aturan asosiasi yang mempunyai hubungan kuat:

Beverages $\rightarrow$ cemilan dengan nilai confidence sebesar $41.925 \%$

Biskuit $\rightarrow$ coklat dengan nilai confidence sebesar 36 $\%$

Tisu $\rightarrow$ parfum dengan nilai confidence sebesar $33.333 \%$

Beberapa contoh aturan asosiasi yang mempunyai hubungan sedang adalah :

Biskuit $\rightarrow$ permen dengan nilai confidence sebesar $28 \%$

Cemilan $\rightarrow$ biskuit dengan nilai confidence sebesar $20 \%$

Susu bayi $\rightarrow$ coklat dengan nilai confidence sebesar $17.857 \%$

Beberapa contoh aturan asosiasi yang mempunyai hubungan lemah adalah :

Cemilan $\rightarrow$ permen dengan nilai confidence sebesar $14.545 \%$

Obat $\rightarrow$ biskuit dengan nilai confidence sebesar $14.286 \%$

Cemilan $\rightarrow$ sabun cuci dengan nilai confidence sebesar $9.091 \%$

\section{Analisa Layout Awal dan Layout Usulan}

Pada saat ini penyusunan item yang ada pada XX swalayan sepenuhnya ditentukan oleh pihak XX swalayan sendiri berdasarkan kepada kebijakan dari pemilik swalayan.

Berdasarkan layout awal tersebut penyusunan item dilakukan secara acak dan masih belum maksimal. Dengan menerapkan MBA dengan disini diharapkan dapat membantu dalam penyusunan layout barang yang lebih baik lagi berdasarkan pola pembelian pelanggan. Pola pembelian konsumen didiskripsikan dengan aturan asosiasi dan hubungan antar item didiskripsikan pada hasil ARC. ARC diSusu bayin dari nilai confidence yang menunjukkan kuat, sedang dan lemahnya hubungan antar item dari hasil ini kemudian dapat diusulkan design suatu layout dimana letak beberapa cluster didekatkan berdasarkan hubungan dan tingkat confidence yang dihasilkan dan selebihnya cluster yang ada dapat menyesuaikan dengan kondisi bangunan untuk diletakkan dimana saja. Menurut hasil dari aturan asosiasi yang diperoleh, adapun beberapa cluster yang dianjurkan untuk didekatkan berdasarkan urutannya adalah cluster beverages dan cluster biskuit dengan cluster permen, cluster beverages dengan cluster cemilan, cluster cemilan dan cluster biskuit dengan cluster sabun cuci, cluster biskuit dengan cluster coklat, cluster tisu dengan parfum, cluster handbody dengan parfum, cluster biskuit dengan cluster permen, cluster beverages dan cluster cemilan dengan cluster permen, cluster cemilan dengan cluster biskuit, cluster cemilan dengan cluster coklat, cluster beverages dengan cluster permen, cluster beverages dengan cluster Susu bayi, cluster biskuit dengan cluster mie instant, cluster biskuit dengan cluster wafer, cluster beverages dan cluster cemilan dengan cluster biskuit, cluster beverages dan cluster cemilan dengan cluster wafer, cluster cemilan dan cluster permen dan lain-lain. Dari aturan asosiasi yang terbentuk diatas, beberapa cluster yang mengalami perubahan adalah sebagai berikut cluster permen menjadi cluster biskuit, cluster sandal menjadi cluster permen, cluster biskuit menjadi cluster coklat, cluster wafer menjadi cluster Susu bayi, cluster coklat menjadi cluster wafer, cluster handbody menjadi cluster obat, cluster sikat gigi menjadi cluster tisu, cluster sabun menjadi cluster parfum, cluster sampo menjadi cluster handbody, cluster pakaian dalam menjadi cluster sikat gigi, cluster tisu menjadi cluster sabun, cluster pembalut menjadi cluster sampo, cluster parfum menjadi cluster pembalut, cluster obat menjadi cluster sandal, cluster Susu bayi menjadi cluster roti, cluster roti menjadi cluster pakaian dalam.

\section{Analisa aplikasi MBA}

Salah satu aplikasi dari MBA adalah layout. Seperti yang telah dibahas sebelumnya layout usulan didapatkan dari nilai confidence yang mempunyai pengertian jika seseorang membeli item $X$ cenderung membeli item $Y$. Sebenarnya dari nilai confidence ini juga dapat memberikan banyak informasi sebagai aplikasi MBA yang lain seperti pemasangan iklan di item $X$ menuju B dari analisis tersebut diharapkan dengan melihat iklan yang terpasang pada item $X$ maka pelanggan akan tertarik untuk membeli item $Y$. Aplikasi lain yang didapatkan dari MBA adalah dengan sistem hadiah. Aplikasi ini dapat diterapkan pada item yang sering terjual yang dapat diketahui berdasarkan database, dengan item yang jarang 
terbeli atau item yang tidak frequent. Dari informasi tersebut item yang tidak sering terbeli dipasangkan pada item yang sering terbeli sebagai bonus, dari stategi seperti itu pelanggan akan lebih tertarik untuk membeli, sedangkan keuntungan yang didapatkan swalayan adalah untuk menurunkan item yang tidak laku jual

\section{Kesimpulan}

Berdasarkan hasil pengolahan data dan pembahasan pada penelitian di XX Swalayan dapat diambil suatu kesimpulan bahwa :

Berdasarkan hasil aturan asosiasi yang diperoleh dari teknik MBA dengan menggunakan metode Pattern Growth diketahui beberapa cluster yang mempunyai hubungan untuk dibeli oleh pelanggan secara bersamaan. Beberapa contoh cluster tersebut diantaranya cluster beverages dengan cluster cemilan, cluster biskuit dengan cluster coklat, cluster tisu dengan cluster parfum, cluster handbody dengan parfum, cluster biskuit dengan cluster permen dan lain-lain. Perancangan layout usulan cluster berdasarkan analisa hubungan dan kebiasaan pelanggan. Hubungan antara produk yang kuat berarti mempunyai kecenderungan untuk didekatkan. Sehingga pada layout usulan, cluster tersebut dapat diletakkan berdekatan sesuai hasil dari hasil ARC dan nilai confidence antar item dari aturan asosiasi. Selebihnya cluster yang ada dapat menyesuaikan dengan kondisi bangunan untuk diletakkan dimana saja.

\section{Daftar Pustaka}

[1] Annisa et. al., (2007). pencarian target event rules dengan metode pattern growth. Proceeding of national conference computer science \& information technology. faculty of computer science University of Indonesia.

[2] Budiarti, A. et. al., (2006). studi karakteristik kelulusan peserta didik dengan teknik clustering. seminar nasional sistem dan informatika, Bali.

[3] Berry, M.J.A dan Linoff, G.S., (2004). data mining techniques for marketing, sales, and costumer relationship management second edition. John Wiiley, Inc. Indianapolis, Indiana
[4] Boztu g, Y. dan Hildebrandt, L., (2005). a market basket analysis conducted with a multivariate logit model. Berlin, Germany. 110.

[5] Djunaidy dan Soelaiman, (2001). perbandingan kinerja perangkat lunak data mining untuk pencarian pola asosiasi dengan metode graf asosiasi dimensi fractal. jurnal ilmu komputer dan teknologi informasi, vol.1 no.2, 1-10.

[6] Fayyad, et. al., (1996). from data mining to knowledge discovery in databases. Artificial Intelligence American Association for Artificial Intelligence, 31-54.

[7] Gunawan, R., (2003). pencarian pola darl data web server log dengan menggunakan teknik association rule. jurnal Sigma, vol. 6 no.1, 4350.

[8] Han, J. dan Kamber, M., (2001). data mining : concepts and techniques, Morgan Kaufmann.

[9] Koh, H. C. dan Low, C. K., (2004). going concern prediction using data mining techniques. Managerial Auditing Journal, vol. 19 no. 3, 462-476.

[10] Kapiudin, M., (2007). data mining untuk klasifikasi pelanggan dengan ant colony optimization. Jurnal Informatika, vol. 8 no. 1, 68-73.

[11] Netz et. al., (2000). integration of data mining and relational databases. Proceedings of the 26th International Conference on Very Large Databases, Cairo, Egypt, digi Mine, Inc.

[12] Pramudiono, I., (2003). pengantar data mining: menambang permata pengetahuan di gunung data. IlmuKomputer, 1-4.

[13] Purnomo, H., (2004). perencanaan dan perancangan tata letak fasilitas. Yogyakarta, Graha Ilmu

[14] Santoso, B., (2007). Data mining Teknik Pemanfaatan Data Untuk Keperluan Bisnis. Yogyakarta, Graha Ilmu.

[15] Santoso, L. W., (2003). pembuatan perangkat lunak data mining untuk penggalian kaidah sosiasi menggunakan metode apriori. jurnal informatika, vol. 4 no. 2, 49-56.

[16] Suwarningsih, W., (2008). Penerapan Association Rule Mininguntuk Perancangan Data Mining BDP (Barang Dalam Proses) Obat. jurnal teknologi industri,vol. 12 no.1, 1926. 
[17] Samuel, D., (2007). penerapan stuktur fp-tree dan algoritma fp-growth dalam optimasi penentuan frequent itemset. Bandung, Institut Teknologi Bandung: 1-6.
[18] Surjandari, I. dan Seruni A. C., (2005). design of product placement layout in retail shop using market basket analysis. makara teknologi journal, vol 9 no. 2,43-47 